\title{
Cardiopulmonary Bypass for Tracheal Resection and Repair-A Safe Alternative
}

\author{
Akshay Chauhan ${ }^{*}$, Satish Kumar Aggarwal ${ }^{2,3}$, Vishnu Dutt' ${ }^{4}$, Saket Agarwal', M. A. Geelani ${ }^{1}$ \\ ${ }^{1}$ Department of Cardiothoracic and Vascular Surgery, G B Pant Hospital, New Delhi, India \\ ${ }^{2}$ Department of Pediatric Surgery, Maulana Azad Medical College, New Delhi, India \\ ${ }^{3}$ Department of Pediatric Surgery, Sir Ganga Ram Hospital, New Delhi, India \\ ${ }^{4}$ Department of Anaesthesia, G B Pant Hospital, New Delhi, India \\ Email: ^dr.akshaychauhan1990@gmail.com
}

How to cite this paper: Chauhan, A., Aggarwal, S.K., Dutt, V., Agarwal, S. and Geelani, M.A. (2018) Cardiopulmonary Bypass for Tracheal Resection and Repair-A Safe Alternative. World Journal of Cardiovascular Surgery, 8, 197-203.

https://doi.org/10.4236/wjcs.2018.811019

Received: October 6, 2018

Accepted: November 4, 2018

Published: November 7, 2018

Copyright $\odot 2018$ by authors and Scientific Research Publishing Inc. This work is licensed under the Creative Commons Attribution International License (CC BY 4.0).

http://creativecommons.org/licenses/by/4.0/

\begin{abstract}
Airway management during tracheal surgery is always challenging for the anaesthesia team. Cardiopulmonary bypass $(\mathrm{CPB})$ is generally not required during tracheal surgery on the cervical trachea. However, for tracheal surgeries $\mathrm{CPB}$ may be advantageous and give the surgeon more freedom to work. We report three cases of post-intubation tracheal stenosis successfully managed with tracheal resection and reconstruction performed under cardiopulmonary bypass.
\end{abstract}

\section{Keywords \\ Cardiopulmonary Bypass, Tracheal Stenosis}

\section{Introduction}

Critically ill patients are frequently managed with endotracheal intubation and prolonged ventilation. Although design of low pressure high volume cuff in endotracheal/tracheostomy tubes has significantly reduced the incidence of post-intubation tracheal stenosis, it still remains a matter of concern. Though most develop stenosis after prolonged periods of intubation, it can occur after as short a period as 48 hours of intubation [1]. Tracheostomy done for prolonged ventilation can also lead to similar devastating outcomes. Symptoms can occur abruptly or gradually, depending upon the pathology, severity and location of the lesion. Management usually involves resection of the diseased tracheal segment with end to end anastomosis. During tracheal resection and reconstruction for tracheal stenosis cardiopulmonary bypass is usually not used. But from our 
experience of three cases of low tracheal stenosis, we have found CPB useful to facilitate tracheal surgery.

\section{Case 1}

A 10-year-old girl was referred to us for management of post intubation tracheal stenosis. She had required endotracheal intubation for a week following head injury sustained in a road accident three months prior. She later developed stridor and difficulty in breathing, and imaging (CT) confirmed mid tracheal stenosis. Bronchoscopy revealed non dilatable tracheal stenosis about four rings above the carina. A diagnosis of cuff induced tracheal stenosis was made. In view of a low but short stenosis a tentative plan for resection and end-to-end anastomosis under cardiopulmonary bypass was made. Inhalational induction of anesthesia with sevoflurane (5\% - 7\%) was done after which it was switched off and anesthesia depth was increased with fentanyl $(2 \mathrm{mcg} / \mathrm{kg})$ and endotracheal intubation with a small size tube was facilitated with rocuronium $(1 \mathrm{mg} / \mathrm{kg})$. Midline sternotomy was performed and distal trachea dissected through aortopulmonary window. Aortic and right atrial cannulation was done and the patient was placed on cardiopulmonary bypass after adequate heparinization. Cardiopulmonary bypass was conducted at normothermia and heart was not arrested. The endotracheal tube was removed. Resection of the stenosed tracheal segment with end to end anastomosis was performed with interrupted PDS sutures. The neck was kept flexed to decrease the tension on the suture line. Endotracheal tube was inserted under guidance and CPB discontinued. Cardiopulmonary bypass time was 75 minutes. The patient had uneventful postoperative recovery. The endotracheal tube was removed on $7^{\text {th }}$ postoperative day and she was discharged after three days of observation.

\section{Case 2}

A 22-year-old young man sustained head injury following a fall from height. Patient was taken to a peripheral hospital where tracheostomy was done to secure the airway after an unsuccessful attempt at intubation. After ventilatory support of two days, patient's neurological status improved. He was weaned off the ventilator on the $5^{\text {th }}$ day but decannulation was not tolerated. Four months later he was referred to us. CT, bronchoscopy and virtual bronchoscopy revealed tracheal stenosis at the site of the tracheostomy with distal extension of about $3 \mathrm{~cm}$ creating a tunnel like stenosis of the trachea. It was a low tracheostomy.

He was taken up for elective surgery. Anaesthesia was induced via the tracheostomy in situ. Intravenous induction of anesthesia was performed with fentanyl $(5 \mathrm{mcg} / \mathrm{kg})$ and thiopentone $(1 \mathrm{mg} / \mathrm{kg})$ with pancuronium $(0.1 \mathrm{mg} / \mathrm{kg}) . \mathrm{A}$ transverse neck incision around the tracheostomy was made to dissect the cervical portion. Mid line sternotomy was performed to secure CPB with aorto-right atrial cannulation. The stenosed segment was resected and end to end anastomosis performed. Cardiopulmonary bypass was discontinued following a 
fresh endotracheal tube inserted across the newly constructed trachea. Cardiopulmonary bypass time was 64 minutes. The chin was fixed to the chest to prevent hyperextension of neck. The fixation suture was removed on $8^{\text {th }}$ postoperative day.

In post-operative course, patient did not have any cardiopulmonary bypass related complications. Total $800 \mathrm{ml}$ of the blood products were used including packed red cells and fresh frozen plasma. The patient was discharged on the $12^{\text {th }}$ post-operative day. Patient remains asymptomatic on one year follow-up, but was lost to follow up thereafter.

\section{Case 3}

A 14-year-old young boy sustained a head trauma in a road traffic accident and was subsequently transferred to a nearby hospital. Because of poor neurological status, patient was intubated and managed in the Intensive Care Unit. Seven days later, elective tracheostomy was done. As the neurological status of patient improved with medical management, he was gradually weaned off the ventilator and tracheostomy removal trial was given, which was not tolerated. After several unsuccessful attempts to remove tracheostomy, a metallic tracheostomy tube was inserted and patient was discharged home with the same. Multiple attempts were done to dilate the tracheal stenosis by endobronchial route. Patient was referred to our hospital with complaints of increasing difficulty in breathing. Computed tomography showed a long segment tracheal stenosis identified distal to the metallic tube (Figure 1). The stenotic segment was well beyond the reach of metallic tube. Patient was taken up for tracheal reconstructive surgery.

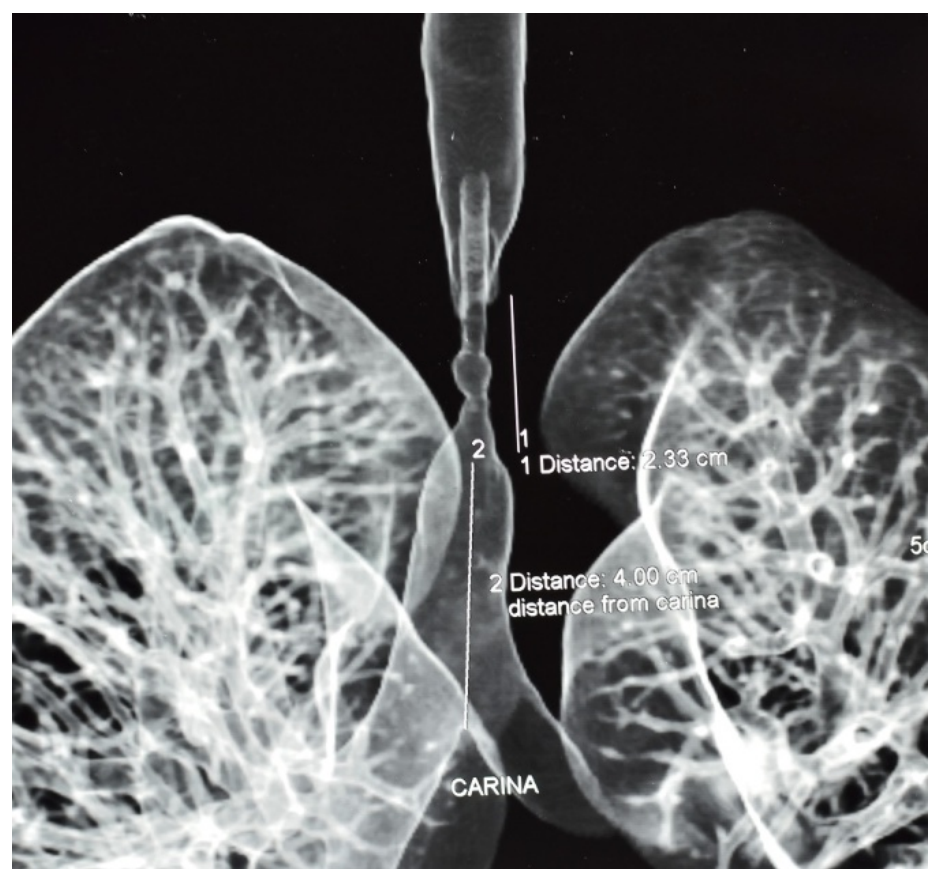

Figure 1. Computed tomographic scan with 3-D reconstruction demonstrating the stenosed tracheal segment. 
Induction of the anaesthesia was done through the metallic tracheostomy tube with the same protocol as case 2. Midline sternotomy was performed and trachea dissected off the adhesions. Patient was heparinized and placed on cardiopulmonary bypass. A long stricture in the trachea starting about 3 rings above the carina was identified. It included the tracheostome. The trachea above the tracheostome was normal. The stricture was opened longitudinally and a costal cartilage graft was used to augment the trachea (Figure 2). An uncuffed tube was positioned across the reconstructed trachea. Cardiopulmonary bypass time was 102 minutes.

Post-operative course of the patient was uneventful. Patient was electively ventilated through the uncuffed endotracheal tube for seven days in view of extensive tracheal reconstruction. The endotracheal tube was removed on 8th postoperative day. The patient was discharged after four more days of observation. He required follow up bronchoscopy for removal of granulations.

Summary of all the three cases is described in Table 1. Informed consent was taken for all the three cases.

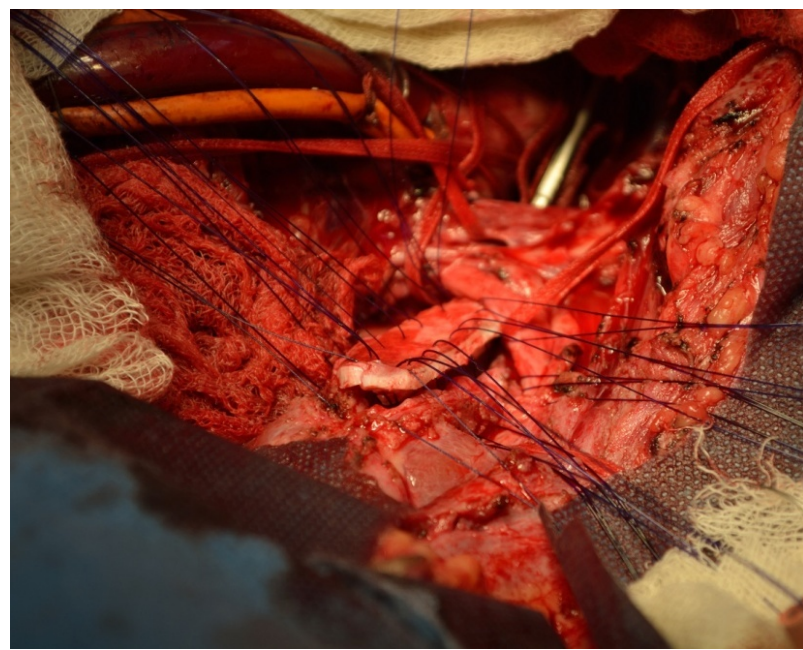

Figure 2. Costal cartilage graft being used to augment the stenosed tracheal segment.

Table 1. Summary of operated cases.

\begin{tabular}{|c|c|c|c|}
\hline & Case 1 & Case 2 & Case 3 \\
\hline Age & 10 years & 18 years & 14 years \\
\hline Sex & Female & Male & Male \\
\hline Cause of tracheal stenosis & Post-intubation & Post-intubation & Post-tracheostomy \\
\hline Level of tracheal stenosis & Level of cuff & Level of cuff and distal & Level of cuff and distal \\
\hline Length of the stenosis & $1.63 \mathrm{~cm}$ & $2.50 \mathrm{~cm}$ & $2.33 \mathrm{~cm}$ \\
\hline Procedure done & Resection and end to end anastomosis & Resection and end to end anastomosis & Cartilage graft tracheoplasty \\
\hline Induction of Anasthesia & Endotracheal tube & Tracheostomy & Tracheostomy \\
\hline CPB time & 75 mins & 64 mins & 102 mins \\
\hline Total Operative time & 210 mins & 185 mins & 250 mins \\
\hline
\end{tabular}




\section{Discussion}

Airway management in tracheal surgery requires a fine coordination between anesthetic and surgical team. The airway is usually managed by cannulating the distal trachea after resection and performing anastomosis around the endotracheal tube.

Usually, cardiopulmonary bypass is used only when a loss of airway is anticipated at the time of induction [2], when distal resection of trachea is to be performed or associated congenital cardiac anomalies are to be treated [3] [4]. Cardiopulmonary bypass has been used as a first line airway management in few cases of nearly complete airway occlusion [5] [6]. It ensures adequate oxygenation in these patients.

The use of cardiopulmonary bypass in pediatric patient is also reasonable considering the smaller airway, leaving the anesthetist team with fewer maneuvers before total obstruction. Cross table ventilation after opening airway distal to stenosis can obscure the operative site and in some cases might even be technically impossible. This can be avoided by cardiopulmonary bypass. One of the largest case series presented by Manning et al. of slide tracheoplasty concluded that these procedures can be done with low mortality and morbidity when performed under cardiopulmonary bypass. Even though the bypass time was one of the independent predictors of longer hospital stay, it correlated with complexity of associated cardiac disease and overall did not appear to adversely influence survival [3].

There are other case reports also suggesting safety and feasibility of cardiopulmonary bypass in oxygenation during tracheal surgery in infants [7] and adults [8] [9]. Bricker Donald et al. recommended that the use of cardiopulmonary bypass should not be considered a morbid procedure for the patient [9].

Although it is an easy way to ensure gas exchange, systemic anticoagulation theoretically increases the risk of bleeding, especially if the dissection is extensive and lung manipulation unavoidable. Rarely pulmonary intraparenchymal hemorrhage has been reported in patients undergoing tracheal reconstructions on cardiopulmonary bypass [10].

Although access site for extracorporeal circulation depends primarily on the planned surgery, apart from aortobicaval cannulation, femoro-femoral bypass can also be used for extracorporeal circulation in lung and tracheal surgeries where the approach is thoracotomy. Lesions involving the lower thoracic trachea are approached usually via right posterolateral thoracotomy or a sternotomy. Conventional cannulation of the aorta and right atrium would be difficult in a thoracotomy [11]. Another scenario where femoral cannulation may be useful is in patients with critical tracheal stenosis or failed intubation where oxygenation maybe achieved by initially taking the patient on femoral bypass under regional anaesthesia and then proceeding with general anesthesia, thus avoiding the need to secure airway.

In our cases, we found cardiopulmonary bypass as a safe alternative. All the 
three cases had a smooth post-operative course and were discharged by $10^{\text {th }}$ $12^{\text {th }}$ postoperative day. No significant blood loss was noted. Intra-operatively, we found it relatively easy to reconstruct the trachea. We recommend the cardiopulmonary bypass in complex tracheal reconstructions as it allows the operating surgeon concentrating only on the surgical aspect rather than the airway management. The surgery is conducted smoothly without any hassle of changing the tubes, cannulating the distal trachea with a separate tube and suturing around the tube. Performing complex procedure like costal cartilage flap reconstruction becomes easier.

\section{Conclusion}

Cardiopulmonary bypass is an effective method which can be used to oxygenate patient during difficult tracheal surgeries where airway control is predictably difficult or impossible. It poses no significant risk to the patient and is an important tool for a thoracic surgeon.

\section{Conflicts of Interest}

The authors declare no conflicts of interest regarding the publication of this paper.

\section{References}

[1] Grillo, H.C. (2000) Surgical Anatomy of the Trachea and Techniques of Resection. In: Shields, T.W., LoCicero III, J. and Ponn, R.B., Eds., General Thoracic Surgery, Vol. 1, $5^{\text {th }}$ Edition, Lippincott Williams \& Wilkins, Philadelphia, 873-883.

[2] Chiu, C., The, B. and Wang, C. (2003) Temporary Cardiopulmonary Bypass and Isolated Lung Ventilation for Tracheal Stenosis and Reconstruction. British Journal of Anaesthesia, 91, 742-744. https://doi.org/10.1093/bja/aeg244

[3] Manning, P.B., Rutter, M.J., Lisec, A., Gupta, R. and Marino, B.S. (2011) One Slide Fits All: The Versatility of Slide Tracheoplasty with Cardiopulmonary Bypass Support for Airway Reconstruction in Children. The Journal of Thoracic and Cardiovascular Surgery, 141, 155-161. https://doi.org/10.1016/j.jtcvs.2010.08.060

[4] Joshi, A., Agarwal, S., Aggarwal, S., Datt, V.R., Sethi, G. and Kumar Satsangi, D. (2013) Single Stage Repair of Tetralogy of Fallot Associated with Left Pulmonary Artery Sling and Tracheal Stenosis. Journal of Cardiac Surgery, 28, 595-598. https://doi.org/10.1111/jocs.12192

[5] Coles, J., Doctor, A., Lefcoe, M. and Butlin, G. (1977) A Method of Anesthesia for Imminent Tracheal Obstruction. Survey of Anesthesiology, 21, 151-152. https://doi.org/10.1097/00132586-197704000-00030

[6] Wilson, R.F., Steiger, Z., Jacobs, J., Sison, O.S. and Holsey, C. (1984) Temporary Partial Cardiopulmonary Bypass during Emergency Operative Management of near Total Tracheal Occlusion. Anesthesiology, 61, 103-105. https://doi.org/10.1097/00000542-198407000-00024

[7] Louhimo, I. and Leijala, M. (1987) Cardiopulmonary Bypass in Tracheal Surgery in Infants and Small Children. In: Wurnig, P., Ed., Trachea and Lung Surgery in Childhood, Springer Berlin Heidelberg, 58-63.

[8] DeWitt, R.C. and Hallman, C.H. (2004) Use of Cardiopulmonary Bypass for Tracheal Resection: A Case Report. Texas Heart Institute Journal, 31, 188. 
[9] Bricker, D.L., Parker, T.M. and Dalton Jr., M.L. (1979) Cardiopulmonary Bypass in Anesthetic Management of Resection: Its Use for Severe Tracheal Stenosis. Archives of Surgery, 114, 847. https://doi.org/10.1001/archsurg.1979.01370310089016

[10] Grillo, H.C. (1982) Carinal Reconstruction. The Annals of Thoracic Surgery, 34, 356-373. https://doi.org/10.1016/S0003-4975(10)61394-X

[11] Jensen, V., Milne, B. and Salerno, T. (1983) Femoro-Femoral Cardiopulmonary Bypass Prior to Induction of Anaesthesia in the Management of Upper Airway Obstruction. Canadian Anaesthetists' Society Journal, 30, 270-272.

https://doi.org/10.1007/BF03013806 